\title{
Electron Beam Induced Modification of Polymer-Like Carbon Coatings
}

\author{
R. Plaipaité-Nalivaiko*, D. Adlienė and G. Adlys \\ Kaunas University of Technology, Physics Department \\ Studentụ str. 50, LT-51368, Kaunas, Lithuania
}

\begin{abstract}
Carbon coatings can possess diamond-like, polymer-like, graphite-like or other properties depending on deposition methods and technological parameters. Structural changes in the polymer-like carbon coatings irradiated by high energy electrons are discussed in the present paper. The polymer-like carbon coatings have been synthesized from $\mathrm{C}_{2} \mathrm{H}_{2}$ gas in the radio frequency dual-plasma reactor using various deposition parameters. Plasma enhancement chemical vapor deposition deposited experimental polymer-like carbon samples were irradiated with high energy electrons in the medical linear accelerator. The investigations of carbon coatings have been carried out using the Fourier-transform infrared, Raman and UV-VIS spectroscopies. Modification of the polymer-like carbon coatings is discussed in relation with radiation induced formation of free radicals and unsaturated bonds along with possible cross-linking processes.
\end{abstract}

DOI: 10.12693/APhysPolA.123.871

PACS: 78.70.-g, 78.66.-w, 78.30.-j

\section{Introduction}

The polymer-like carbon (PLC) coatings attract the interest of scientists due to their ability to protect surfaces of electromechanical and electronic devices and potential applications in chemical sensors and drug delivery. It is known that modification of polymers is possible irradiating them with high energy photons, ions and electrons. Electron beam irradiation has been widely used to modify the surface or bulk properties of polymeric biomaterials and to sterilize them in a cost-effective way. Wagenknecht et al. [1] have shown that high energy electrons may induce not only degradation but grafting, curing and cross-linking or chain scission of polymers.

Possible modification of the PLC coatings upon their interaction with high energy electrons could be very attractive since radiation may induce nanoclusterization within the polymeric matrix and lead to the formation of new structures characterized by new properties [2]. Modification of amorphous hydrogenated diamond-like carbon coatings using high energy photons and electrons has been observed and investigated in our previous papers $[3,4]$. The hydrogenated carbon films - polymeric $\mathrm{a}-\mathrm{C}: \mathrm{H}$ or soft $\mathrm{a}-\mathrm{C}: \mathrm{H}$, are characterized by a wide optical band gap (over $1.8 \mathrm{eV}$ up to $4 \mathrm{eV}$ ) and they can exhibit special optical absorption, intense photoluminescence and electron affinity [5]. Due to the chosen pressure and gas mixture, at low bias voltage deposited coatings have a large $\mathrm{H}$ and $s p^{3}$ content and low density, or else $s p^{2}$ sites form olefinic chains and small clusters that tend to be aromatic $[6,7]$.

\footnotetext{
* corresponding author; e-mail:

rita.plaipaite-nalivaiko@stud.ktu.lt
}

The main aim of this work was to investigate high energy electron radiation induced modification of PLC coatings using the Fourier transform infrared, Raman and UV-VIS spectroscopies and discuss their structural changes.

\section{Experimental}

Polymer like carbon coatings synthesized at room temperature under almost atmospheric pressure from pure $(99 \%)$ acetylene $\left(\mathrm{C}_{2} \mathrm{H}_{2}\right)$ in the $\mathrm{RF}(13.56 \mathrm{MHz})$ dual-plasma reactor. Crystalline $n$ type $\mathrm{Si}$ was used as a substrate. Prior to deposition the Si substrates were polished and chemically cleaned with acetone and bombarded with argon ions (plasma cleaning). The bias voltage varied from $80 \mathrm{~V}$ to $480 \mathrm{~V}$ as well as the primary ion current varied from 1.0 to $1.4 \mathrm{~mA}$, keeping the gas flow rate of $5.6 \mathrm{~cm}^{3} / \mathrm{s}$. Deposition time of all samples was $420 \mathrm{~s}$.

The freshly deposited samples were divided into two pieces and the sets containing 7 experimental samples each were prepared for the exploration. The samples of the first set (Table I) were not irradiated, however, their properties were investigated in parallel with those of the irradiated samples. The samples of the second set were irradiated by high energy electrons generated in the medical linear accelerator Clinac DMX. The energy of electrons was $12 \mathrm{MeV}$ and the dose rate was $2 \mathrm{~Gy} / \mathrm{min}$. All samples of the second set were exposed to $2 \mathrm{~Gy}$ dose.

Sample thickness was evaluated using the interferometer. The refractive index and the extinction coefficient $k$ were obtained using the laser ellipsometer Gaertner 117 with He-Ne laser $(\lambda=632.8 \mathrm{~nm})$.

The bonding configuration of the samples was studied by means of infrared spectroscopy. The reflectance spectra of samples were measured in the range of 650 $4000 \mathrm{~cm}^{-1}$ using the FTIR spectrometer Nicolet 5700 . 
TABLE I

The characteristics of as prepared PL type carbon coatings with acetylene $\mathrm{C}_{2} \mathrm{H}_{2}$ as precursor gas.

\begin{tabular}{c|c|c|c|c|c}
\hline \hline ID no. & $U[\mathrm{~V}]$ & $I[\mathrm{~mA}]$ & $n$ & $k$ & $d[\mathrm{~nm}]$ \\
\hline RP3 & 80 & 1.166 & 1.66 & 0.007 & 790 \\
RP4 & 100 & 0.043 & 1.64 & 0.006 & 1063 \\
RP5 & 120 & 0.034 & 1.67 & 0.013 & 748 \\
RP6 & 200 & 0.014 & 1.74 & 0.002 & 940 \\
RP7 & 300 & 0.083 & 1.73 & 0.006 & 967 \\
RP8 & 400 & 1.161 & 1.66 & 0.007 & 946 \\
RP9 & 480 & 1.355 & 1.77 & 0.009 & 810
\end{tabular}

The Raman spectra of experimental samples were measured using the Ivon Jobin spectrometer with a Spectra Physics Nd:YAG laser $(\lambda=532.3 \mathrm{~nm}, 50 \mathrm{~mW}$ at a $0.3 \mathrm{~mm}$ spot size). The assignment curves were fitted with two Gaussian shapes at a linear background. RS were estimated in the range of $400-2000 \mathrm{~cm}^{-1}$ but the fitting process was carried out for the $1200-1800 \mathrm{~cm}^{-1}$ range, respectively.

Optical reflectance spectra of the samples were characterized using the USB4000-UV-VIS spectrometer. The USB4000-UV-VIS spectrometer was pre-configured with the order-sorting filter to cover the $200-850 \mathrm{~nm}$ wavelength range.

\section{Results and discussion}

\subsection{FTIR spectroscopy}

The FTIR reflectance spectra of as prepared RP3 sample and the same high energy irradiated sample RE3 are shown in Fig. 1.

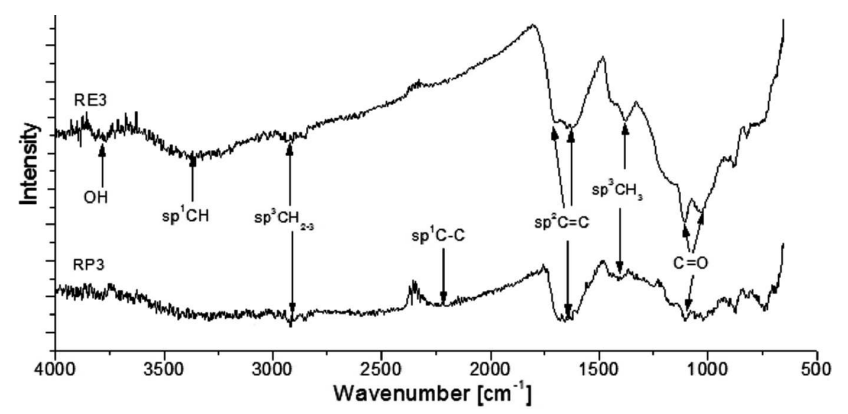

Fig. 1. FTIR reflectance spectra of RP3 sample before and after irradiation with high energy electrons (RE3).

The FTIR spectra show $s p^{3} \mathrm{CH}_{2-3}$ (methylene) groups in asymmetric and symmetric stretching and bending modes at $\approx 2900 \mathrm{~cm}^{-1}$. It is clearly seen that radiation induces defects and dangling bonds that can be easily occupied by oxygen as well as creates $\mathrm{C}=\mathrm{O}$ and $\mathrm{O}-\mathrm{H}$ bonds [8]. Intensive peaks at $1723 \mathrm{~cm}^{-1}$ and $1107 \mathrm{~cm}^{-1}$ (RE3 sample) are related to $s p^{2} \mathrm{C}=\mathrm{O}$ stretching vibrations; the broad band ranging from $3300-3700 \mathrm{~cm}^{-1}$ corresponds to the valence and deformation vibrations of $\mathrm{O}-\mathrm{H}$ group. Part of these peaks might be related to $s p^{1}$ carbon $(\mathrm{C} \equiv \mathrm{C}-\mathrm{H})$. The fraction of $s p^{3} \mathrm{CH}_{3}$ at $1390 \mathrm{~cm}^{-1}$ increases depending on the type of radiation. The same confirmation is valid for the growing peak at $\approx 1642 \mathrm{~cm}^{-1}$ which is attributed to the vibration mode of $s p^{2} \mathrm{C}=\mathrm{C}$ and indicates the presence of aromatic and olefinic configuration of the bonds. It is important to note that the irradiation with high energy electrons has greater impact on substrates than irradiation with gamma photons [8].

\subsection{Raman spectroscopy}

The Raman spectra (RS) of PLC coatings are presented in Fig. 2. The $D$ and $G$ bands were fitted simultaneously by two Gaussian shapes at a linear background. $G$ position is chosen as the maximum of the function rather than its center, to allow comparison with the symmetric curve fits.

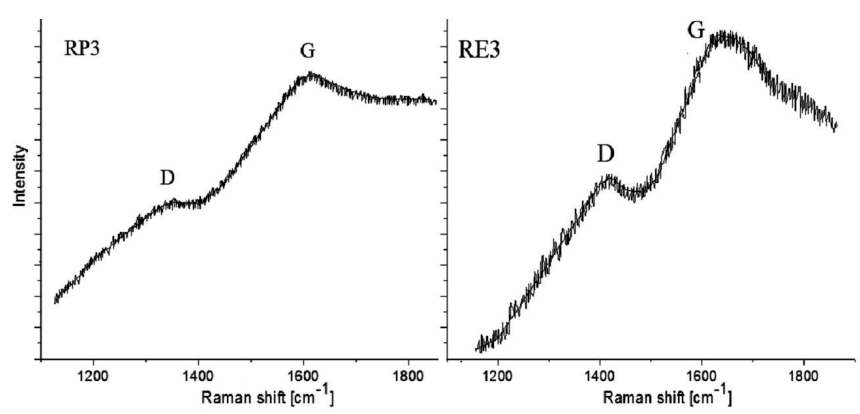

Fig. 2. Raman spectra of RP3 sample before irradiation and after modification.

Analyzing the RS results Ferrari and Robertson [5] have proposed that $G$ peak observed in the 1500$1630 \mathrm{~cm}^{-1}$ range is due to the bond stretching of all $s p^{2}$ sites in rings and chains. The $D$ peak becomes active only in the presence of disorder.

It was found that the RS spectrum of as prepared RP3 sample consists of $D\left(1380 \mathrm{~cm}^{-1}\right)$ and $G\left(1592 \mathrm{~cm}^{-1}\right)$ peaks. The full width at half-maxima (FWHM) of the $D$ and $G$ peaks is $250 \mathrm{~cm}^{-1}$ and $130 \mathrm{~cm}^{-1}$, respectively. The integral intensity ratio between the $D$ and $G$ peaks $I_{D} / I_{G}$ is 1.41 . These findings indicate that most probably the coatings are polymer-like and contain a considerably large number of $s p^{3}$ bonds. However, the $D$ and $G$ peaks of the RS spectra for the RE3 coating (with modification of high energy electrons) are shifted to a higher wave number due to the increase of $s p^{2}$ sites. The $D$ $\left(1410 \mathrm{~cm}^{-1}\right)$ and $G\left(1625 \mathrm{~cm}^{-1}\right)$ peaks become more intensive. The intensity of the $D$ peak increases because of conversion of $s p^{3}$ to $s p^{2}$ bonds, desorption of hydrogen and conversion of carbon structure to nanocrystalline graphite [7]. The $G$ peak value of $1625 \mathrm{~cm}^{-1}$ is attributed to $s p^{2} \mathrm{C}=\mathrm{C}$ and indicates olefinic configuration of the bonds. Thus the FWHM values of both peaks narrowed to $150 \mathrm{~cm}^{-1}$ and $60 \mathrm{~cm}^{-1}$, respectively. The $I_{D} / I_{G}$ ratio is increased to 1.76 , therefore it is possible to state that this coating becomes more graphite like. The shape of the 
spectrum and small FWHM values indicate that the production of hydrogen leads to the formation of nanocrystalline graphite coating.

The results of Raman spectroscopy

TABLE II

\begin{tabular}{c|c|c|c|c|c|c}
\hline \hline \multirow{2}{*}{$\begin{array}{c}\text { ID } \\
\text { No. }\end{array}$} & \multicolumn{3}{|c|}{$\begin{array}{c}\text { Characteristics of Raman } \\
\text { spectra of as prepared samples }\end{array}$} & \multicolumn{3}{c}{$\begin{array}{c}\text { Characteristics of Raman } \\
\text { spectra of irradiated samples }\end{array}$} \\
\cline { 2 - 7 } & $D\left[\mathrm{~cm}^{-1}\right]$ & $G\left[\mathrm{~cm}^{-1}\right]$ & $I_{D} / I_{G}$ & $D\left[\mathrm{~cm}^{-1}\right]$ & $G\left[\mathrm{~cm}^{-1}\right]$ & $I_{D} / I_{G}$ \\
\hline RP3 & 1380 & 1592 & 1.41 & 1410 & 1625 & 1.76 \\
RP4 & 1371 & 1544 & 1.49 & 1399 & 1581 & 1.64 \\
RP5 & 1368 & 1539 & 1.45 & - & - & - \\
RP6 & 1372 & 1548 & 1.49 & - & - & - \\
RP7 & 1377 & 1555 & 1.48 & - & - & - \\
RP8 & 1376 & 1553 & 1.48 & 1386 & 1587 & 1.68 \\
RP9 & 1381 & 1569 & 1.43 & 1405 & 1609 & 1.73
\end{tabular}

Characteristics of the Raman spectrum of all investigated samples are provided in Table II. According to Robertson [2] while the $G$ peaks width decreases, the Urbach energy continues to increase. The Urbach energy is a value of inhomogeneous disorder that shows the range of $s p^{2}$ cluster sizes present. In such a case, while the Urbach energy increases, inhomogeneous disorder increases and the optical gap of PLC coatings increases, too.

\section{3. $U V$-VIS spectroscopy}

Optical properties of PLC coatings were investigated using the USB4000-UV-VIS spectrometer in the 200$850 \mathrm{~nm}$ wavelength range. The UV-VIS reflectance spectra of the RP3 sample (without modification) and the RE3 sample (after modification) are shown in Fig. 3.

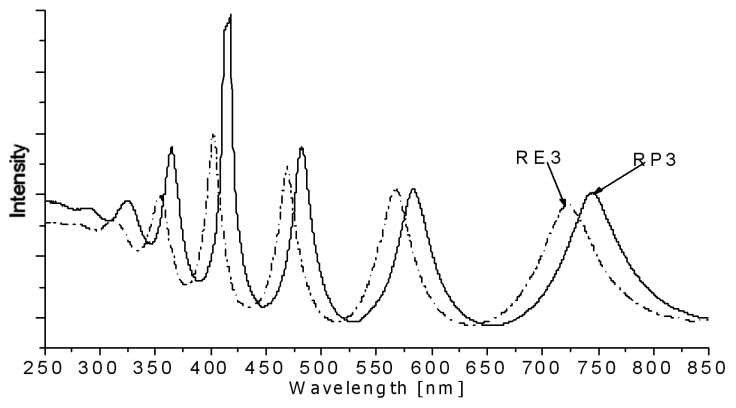

Fig. 3. UV-VIS reflectance spectra of the RP3 sample before irradiation and after modification with high energy electrons (RE3).

Analyzing the spectra, it is clearly seen that the peaks for the RE3 sample are shifted to lower wavelength values as compared to those for the RP3 sample which was not modified. The intensity of the peaks in the case of the RE3 sample case decreases. This indicates that new dangling bonds and chains occur, which are responsible for the changes of PLC coating characteristics. More than 2 or 3 intensive peaks in the spectra indicate aromatic configuration of the bonds.

\section{Conclusions}

Structural changes of the PLC coatings are discussed in association with radiation induced formation of free radicals and unsaturated bonds, which are responsible for possible cross-linking processes in polymers. Increased IR absorption level in all irradiated experimental PLC coatings as well as rearrangements in the bonding structure were observed. Modification of PLC coating properties was discussed in relation to the appearance and disappearance of specific bonds and links. Since the majority of hydrogen content is bonded to the $s p^{3}$ carbon and forms methylene compounds $s p^{3} \mathrm{C}-\mathrm{H}_{2-3}$, appearance of $\mathrm{O}-\mathrm{H}$ and $\mathrm{C}=\mathrm{O}$ bonds in irradiated coatings was related to the hydrogen elimination from the surface and/or creation of radiation defects. This is confirmed by the Raman and UV-VIS spectroscopies.

\section{Acknowledgments}

This article was prepared under partial support of the European Social Fund Agency implementing measure VP1-3.1-ŠMM-08-K of the Human Resources Development Operational Programme of Lithuania 2007-2013 3rd priority "Strengthening of capacities of researchers and scientists" (project No. VP1-3.1-SMM-08-K-01-013). Authors are grateful to Mrs. ̌̌. Rutkūnienè for the Raman measurements.

\section{References}

[1] U. Wagenknecht, U. Gohs, A. Leuteritz, S. Volke, S. Wiessner, G. Heinrich, Macromol. Symp. $\mathbf{3 1}$ 146 (2011)

[2] J. Robertson, Mater. Sci. Eng. R 37, 129 (2002).

[3] D. Adlienè, J. Laurikaitienè, S. Tamulevičius, Nucl Instrum. Methods Phys. Res. B 266, 2788 (2008).

[4] M. Šniurevičùè, J. Laurikaitiee, D. Adliee, L. Augulis, Z. Rutkūnienè, A. Jotautis, Vacuum 83, 159 (2009).

[5] A.C. Ferrari, J. Robertson, Phys. Rev. B 61, 14096 (2000).

[6] C. Godet, T. Heitz, J.E. Bourée, B. Drévillon, C. Clerc, J. Appl. Phys. 84, 3919 (1998).

[7] P.K. Chu, L. Li, Math. Chem. Phys. 96, 253 (2006).

[8] R. Plaipaite-Nalivaiko, D. Adliene, in: Mater. 4th Int. Conf. "Radiation Interaction with Material and Its Use in Technologies 2012", 2012, p. 258. 